\title{
RAPID SAFETY AND QUALITY CONTROL DURING FISH SHELF-LIFE BY USING A PORTABLE DEVICE
}

Running title: Rapid Fish shelf-life control by Food Sniffer

\author{
Marta Castrica ${ }^{a}$, Luca Maria Chiesa ${ }^{a}$, Maria Nobile ${ }^{a}$, Francesca De Battisti ${ }^{b}$, Elena Siletti ${ }^{b}$, \\ Davide Pessina ${ }^{c}$, Sara Panseri ${ }^{a}$, Claudia M. Balzaretti ${ }^{a}$
}

${ }^{a}$ Department of Health, Animal Science and Food Safety, Università degli Studi di Milano, 6 20133 Milan, Italy.

${ }^{\mathrm{b}}$ Department of Economics, Management, and Quantitative Methods, via Conservatorio 7, 20122, Milan, Italy

${ }^{c}$ Quality Department, Italian retail Il Gigante SpA, Milan, Italy

Correspondence should be addressed to:

Sara Panseri; sara.panseri@ unimi.it. Department of Health, Animal Science and Food Safety, Università degli Studi di Milano, 620133 Milan, Italy.

\begin{abstract}
BACKGROUND: Fish consumption is increasing nowadays both because of its positive role for health due to the abundant presence of unsaturated fatty acids and for its use in many new food preparations (e.g. raw fillet used for uncooked sushi and sashimi dishes). The growing food industry and increased demand for the long-term storage and preservation of food have created the need to develop methods that can easily track and preserve food freshness and safety throughout shelf life (production, storage, shipment, and consumption). While e-nose technologies have already been used and tested for these purposes, scarce information is available in literature on the feasibility of using other food devices to detect changes in
\end{abstract}

This article has been accepted for publication and undergone full peer review but has not been through the copyediting, typesetting, pagination and proofreading process which may lead to differences between this version and the Version of Record. Please cite this article as doi: 10.1002/jsfa.10646 
perishable food like fish during shelf life in order to predict and correctly manage all food storage phases. The aim of the present study was to investigate the potential of Food Sniffer ${ }^{\circledR}$ portable devices to define the quality and safety of salmon fillet and burger (Salmo salar) packaged in modified atmosphere at two refrigerated conditions $\left(4\right.$ and $\left.8^{\circ} \mathrm{C}\right)$.

RESULTS: An increase in biogenic amines and volatile compounds especially ketones and alcohols were observed, with large amounts at final storage times of $8^{\circ} \mathrm{C}$ temperature.

CONCLUSION: The Food Sniffer ${ }^{\circledR}$ application was able to anticipate unacceptability conditions of salmon samples also correlated with chemical and microbiological parameters. This could represent a valid support for food industry and retail to manage perishable food commodities preventing possible food risk as well.

Keywords: Food Sniffer ${ }^{\circledR}$; salmon; shelf life; biogenic amine; volatile compounds; microbiological count.

\section{INTRODUCTION}

\section{Trends in Fish Consumption}

Caught or farmed fish is an important source of food and provides an essential contribution to human health given its high protein content but also the wide range of essential micronutrients, including various vitamins, minerals, and polyunsaturated fatty acids (PUFA) of the $\mathrm{n}-3$ family (colloquially, omega-3 fatty acids), mainly eicosapentaenoic acid and docosahexaenoic acid (DHA). ${ }^{1}$ Food fish consumption, in per capita terms, has grown at an average rate of about 1.5 percent per year. In 2016 and 2017 data show further growth to about 20.3 and $20.5 \mathrm{~kg}$, respectively. The expansion in consumption has been driven not only by increased production, but also by a combination of many other factors, including reduced wastage and better utilization 
including improved distribution channels. ${ }^{2}$ Several studies indicate that fish is also perceived as a healthy food by consumers, particularly compared with meat - the main substitute source of protein - but is also more perishable compared to other fresh meat commodities. ${ }^{3}$

The main commercial fish species consumed in the EU are tuna (2.78 kg per capita), cod (2.33 $\mathrm{kg}$ per capita) followed by salmon ( $2.19 \mathrm{~kg}$ per capita $)^{4}$. Despite the high levels of consumption and therefore of production, in 2016 the FAO estimates that about 35\% of all the fish and seafood produced in Europe was lost or wasted along the supply chain. ${ }^{5}$ Among fish species, salmon has a high economic value as a result of a growing demand for this product in international fish markets. Today, especially in European countries, fish consumption is increasing in human diet on the basis of its potential beneficial effect on chronic degenerative diseases. ${ }^{6}$ Moreover, there is a steady growth trend for the consumption of sushi and other new food preparations. ${ }^{78}{ }^{7}$ It is normally consumed fresh, or else is stored frozen or in a refrigerated modified atmosphere before consumption. ${ }^{10,11}$

\section{New Analytical Approaches in the Fisheries Sector}

The growing trend to create more environmentally sustainable food industries is also focusing on the development of innovative packaging that will enable an extension of the shelf life of food in order to reduce food waste. ${ }^{12,13}$

This new "circular development" trend is strongly related to a global call for a reduction in food waste. Indeed, international targets (12.3) aim to halve per capita food waste at a retail and consumer level and reduce food losses along production and supply chains until $2030 .^{14}$ Several changes can occur in packaged food as a result of metabolism or microbial growth over time. For example, changes in gas evolution or microbial accumulation can be used to obtain information about the status of food, e.g., freshness or degradation.${ }^{15}$ The hygienic quality of 
such food declines rapidly due to microbial cross-contamination from various sources, ultimately leading to spoilage ${ }^{16,17}$ Fish possess a diverse array of bacterial taxa, often reflecting the composition of the microflora of the surrounding water. The role of microorganisms in fish product deterioration has been carefully pointed out. Microbial growth and metabolism are responsible for the production of several compounds such as biogenic amines, organic acids, sulphides, alcohols, aldehydes and ketones, accompanied by the development of an unpleasant and unacceptable "off-flavour". ${ }^{18}$ Oxidation of lipids represents a key factor that causes salmon deterioration during refrigerated storage which is the main cause of a reduction in shelf-life. ${ }^{19}$ Lipid oxidation can be either non-enzymatic or enzymatic, leading to the development of rancidity. The speed of degradation is dependent on the type of product, storage temperature, feeding habits, and harvesting methods. ${ }^{20}$ Other biomarkers for the identification of fish degradation are biogenic amines such as putrescine, cadaverine, histamine, tyramine, spermidine, spermine, and tryptamine that accumulate as a result of microbial decarboxylation of amino acids. $^{21}$

Traditional methods to assess freshness especially during shelf-life rely on human senses; although they are essential, they provide no quantitative data for spoiled food. Methods that can quantitatively measure markers of degradation through chemical or biological means are extensively described in the literature and provide accurate information about the status and quality of food. ${ }^{16}$

Microbiological analyses and quantification of volatile organic compounds (VOCs) are often used to evaluate meat, fish, and poultry freshness, for example, VOCs are traditionally detected by headspace techniques coupled to mass-spectrometer. ${ }^{22}$ However, all these analyses have, at present, some limitations: laboratory time, costs and the fact that they must be performed by 
experts. The need for simple, rapid, and field-portable analytical methods for reducing or preventing food loss has boosted the development of biosensors for food analysis. ${ }^{23}$ The integration of biomolecules, such as enzymes, immunosystems, tissues, organelles, or whole cells, with a variety of transduction methods, such as electrical, thermal, or optical signals, has enabled the development of a wide range of biosensing devices. Their selectivity and relative ease of analysis make them advantageous for use in food analysis. ${ }^{24}$ Constant efforts have been made to develop non-destructive sensing methods applicable in situ or in-line to assess food. ${ }^{17}$ Recently, e-nose based or other smart devices (e.g. Food Sniffer ${ }^{\circledR}$ ) have become attractive in food diagnostics for their ability to rapidly detect the deterioration of different perishable matrices such as meat and fish. ${ }^{25}$ Moreover, this smart device can also find application in the third sector such as food banks, where work is done by volunteers without specific training in the food field, and therefore to provide a valid support that is able to interpret the level of freshness of a food might be a requirement to guarantee a safe second life to such items. ${ }^{26,27}$ While E-nose technologies have already been used and tested for these purposes, few applications are available in the literature on the feasibility of using other food devices to detect changes in perishable food like fish during shelf-life in order to predict and to manage all food storage phases correctly. ${ }^{28,29}$ In addition, while significant progress has been achieved at engineering construction level, there is still a need to demonstrate the functionality of biosensing devices in realistic settings for evaluating the quality of packaged food. One of the main challenges in this field is the complexity of food samples and the difficulty in measuring markers of degradation directly in closed packaging without prior sample treatment. ${ }^{30}$ In preliminary research conducted on refrigerated cod fillets (7 days) shelf life was monitored using three different methods: a traditional E-nose, Food Sniffer ${ }^{\circledR}$ and the conventional analysis for the determination of Total 
Volatile Basic Nitrogen (TVB-N) as a standard method of control. Results showed the feasibility of using Food Sniffer ${ }^{\circledR}$ to predict early stage deterioration of cod fillets which has as its primary consequence the formation of food waste. ${ }^{31,32}$ The aim of this experimental study was to apply and validate the use of this portable food diagnostic device - Food Sniffer ${ }^{\circledR}$, in order to test its efficacy, supported by standard laboratory analyses (microbiological and chemical), in order to reveal the changes in the fresh state of salmon (fillets and burgers) packaged in a modified atmosphere during shelf-life and to confirm that the device represents a fast and valid screening method for food business operators and possibly for operators in the third sector.

\section{MATERIALS AND METHODS}

\section{Reagents and chemicals}

Ammonia (25\%), acetone, acetonitrile (high liquid chromatography [HPLC] grade), ammonium acetate, and perchloric acid used in HPLC analysis were from Merck (Darmstadt, Germany). Spermidine trihydrochloride, spermine tetrahydrochloride, 1,7-diaminoheptane as the internal standard (IS), were provided by Sigma (St Louis, MO, USA), while cadaverine dihydrochloride, histamine dihydrochloride, putrescine dihydrochloride and the derivatisation reagent, dansyl chloride were obtained from Acros Organics (Geel, Belgium).

\section{Sample Collection and Experimental Design}

Salmon fillets and burgers were used for this research project in order to monitor changes during shelf-life validating the Food Sniffer ${ }^{\circledR}$ both in fillet and in grounded muscle since the latter is usually more susceptible to oxidation phenomena. The samples were obtained and prepared from three different salmons (Salmo salar) in a retail store in order to apply real conditions. Overall, 
19 fillets and 19 burgers were used for the study, packaged in modified atmosphere and stored at two different conditions $\left(4^{\circ} \mathrm{C}\right.$ and $\left.8^{\circ} \mathrm{C}\right)$ to simulate domestic management. The dimensions of all trays were $17.5 \times 8 \times 2.5 \mathrm{~cm}$. The packaging under modified atmosphere MAP was carried out using a heat sealer Lari3/Pn Cavec T-VG-R-SKIN (Caveco, Milano, Italy). The gas mixture used to package all samples was composed of $66 \% \mathrm{O} 2,25 \% \mathrm{CO}_{2}$ and $9 \% \mathrm{~N}_{2}$ (Aligal 49, Siad, Bergamo, Italy. All evaluations were conducted after 1 day of storage (T0), in which all samples were stored at $4^{\circ} \mathrm{C}$, and for the following days of storage: 3 (T1), 5 (T2), 8 (T3), and 10 (T4), during which each type of sample (burgers and fillets) was divided into two groups, one of which was stored at $4^{\circ} \mathrm{C}$ and the other at $8^{\circ} \mathrm{C}$. Microbiological and physico-chemical analyses were conducted on each sample to validate the Food Sniffer ${ }^{\circledR}$ device during the entire declared shelflife (10 \pm 1 days $)$ in order to simulate retail and domestic conditions.

\section{Food Sniffer ${ }^{\circledR}$ Analysis}

Food Sniffer ${ }^{\circledR}$ rapidly estimates the quality and safety of the raw material correlating it to the levels of volatile organic compounds present in the tested matrix. Functioning of the Food Sniffer ${ }^{\circledR}$ has also been reported in a previous study. ${ }^{33}$

Food Sniffer ${ }^{\circledR}$ device (ARS LAB US), created and validated by scientists and researchers of the Kaunas University of Technology, in cooperation with the company ARS LAB, is a new and fast device used to assess the freshness of food of animal origin.

The results obtained are qualitative outputs associated with color changes: green (the analyzed raw matrix is fresh), orange (the analyzed raw matrix is to be consumed after cooking), and red (the analyzed raw matrix is spoiled). Food Sniffer ${ }^{\circledR}$ rapidly estimates the quality and safety of the raw materials correlating them to the levels of volatile organic compounds present in the 
tested matrix through a gas sensor system including at least two metal-oxide semiconductor sensors configured to measure $\mathrm{NH}_{3}$ and $\mathrm{CH}$ values.

The technology is based on the detection of low concentrations of volatile compounds that are associated with deterioration. The device is composed of a metal-oxide sensor system adapted to respond to the speed of changes in the concentration of volatile compounds, a processor designed to receive and process signals incoming from the sensor system and to turn them into a sequence of electrical signals on the basis of variation in the concentration of volatile compounds, and a Bluetooth device which, according to the algorithms in cloud synchronization, provides the user result to mobile devices (tablets or smartphones) ${ }^{34}$.

\section{Food Sniffer® Analysis Procedure}

In this experimental study all the samples (salmon fillets and burgers) were analyzed with the portable Food Sniffer ${ }^{\circledR}$ device before proceeding with microbiological and chemical-physical analyses and for all the analysis times (0, 3, 5, 8 and 10 days). The samples to be tested were placed in sterile containers, to avoid any contamination, with removable lids. The phases of the analysis were carried out as described below: 1. the device was turned on and connected to the app on a smartphone; 2. the type of matrix to analyze was selected on the app; 3 . the device was introduced inside the container, positioned near the matrix to be analyzed but not in contact with the matrix and then the procedure continued by clicking the "GET" button in the app to start the analysis.

\section{Microbiological analyses}

Microbiological analyses were performed for evaluating quality and safety during sample shelf life. In particular, enumeration of total mesophilic $\left(30^{\circ} \mathrm{C}\right)$ and psychrophilic $\left(22^{\circ} \mathrm{C}\right)$ aerobic 
bacteria, enumeration of Enterobacteriaceae, enumeration of coagulase-positive staphylococci (CPS), enumeration of Escherichia coli, and presence of Salmonella spp. and Listeria monocytogenes were investigated. Furthermore, the following parameters were evaluated to monitor shelf life: Pseudomonas spp. counts, mesophilic and psychrophilic aerobic plate counts and Enterobacteriaceae plate counts were enumerated using a Petrifilm Aerobic Count (3M, St. Paul, Minnesota, USA), following AFNOR 3M 01/1-09/89 and AFNOR 3M 01/06-09/97 respectively. Petrifilm_plates were also used to determine E. coli and CPS, in accordance with the following methods: AFNOR 3M 01/08-06/01 and AFNOR 3M 01/9-04/03 A, respectively. Salmonella spp. detection (analytical unit: 25g) was carried out using UNI EN ISO 6579: 2008. The detection of L. monocytogenes (analytical unit: $25 \mathrm{~g}$ ) was performed according to AFNOR BRD 07/4-09/98 (AFNOR, 2010a). Pseudomonas spp. counts were determined using Cephaloridine Fucidin-Cetrimide selective medium (CFC, OXOID, Basingstoke, Hampshire, UK). All results were expressed as $\log 10 \mathrm{cfu} \mathrm{g}^{-1}$ and performed in duplicate, while for $L$. monocytogenes and Salmonella spp. results were expressed as presence or absence in 25 g/sample. The results obtained from the microbiological analyses (excluding Pseudomonas spp.) were compared to the limits provided by the CeIRSA for the category "fish and fish preparation" (CeIRSA, 2017), (Table 1) as well as being included in the statistical analysis.

\section{Colour measurements}

The color evolution of the individual fish samples (fillet and burger) was determined on the basis of the values of the CIELab system of coordinates immediately after the performance of volatile compound assessment. The measuring procedure was performed according to O'Sullivan and Kerry, 2013. ${ }^{35}$ The parameters of the color space $\mathrm{L}^{*}$-lightness, $\mathrm{a}^{*}$ - redness and $\mathrm{b}^{*}-$ yellowness 
were measured six times for each sample by the reflectance method using a Konica Minolta CM5 Spectrophotometer (Konica Minolta Sensing, Inc., Japan). The instrument was calibrated to white and a setting with D65 light source and measurement slit of $8 \mathrm{~mm}$ was used. Colour measurements were performed directly after opening the package since consumers buying caseready packaged meat evaluate its color at the point of sale, with no blooming.

\section{pH}

The $\mathrm{pH}$ value of samples was measured directly on the fish muscle using a membrane glass probe type electrode (Crisolyt A, Crison PH meter GLP 22, Barcelona, ES).

\section{Biogenic amine determination}

The biogenic amine content was determined according to our previous research on Bluefin tuna.

${ }^{21}$ Briefly, a $4 \mathrm{~g}$ sample was weighed and, after adding $250 \mu \mathrm{L}$ IS and $10 \mathrm{~mL}$ of $0.4 \mathrm{M}$ perchloric acid solution, was homogenized and centrifuged for $10 \mathrm{~min}$ at $2400 \times \mathrm{g}$. The supernatant was transferred into a $25 \mathrm{~mL}$ bottle through filter paper. The extraction was repeated with $10 \mathrm{~mL}$ of $0.4 \mathrm{M}$ perchloric acid solution and centrifuged again. The two supernatants were merged. Subsequently, a derivatization of biogenic amines with dansyl chloride solution $(1 \mathrm{~mL}, 10 \mathrm{mg}$ $\mathrm{mL}^{-1}$ in acetone) was performed at $40 \mathrm{C}$ for $45 \mathrm{~min}$. Remaining derivatization reagent was neutralized by adding $100 \mu \mathrm{L}$ ammonia (25\%). After $30 \mathrm{~min}$, the final extract was adjusted to 5 $\mathrm{mL}$ with $0.1 \mathrm{M}$ ammonium acetate/acetonitrile (1:1) and filtered through a $0.45 \mu \mathrm{m}$ syringe filter (Sartorius, Goettingen, Germany).

The biogenic amines were separated using a HPLC Jasco quaternary pump (Ishikawa-cho, Japan), which was equipped with an autosampler from the same company. Ammonium acetate $0.1 \mathrm{M}$ and acetonitrile adequate elution gradient were applied as mobile phase with a flow rate of 
$1 \mathrm{~mL} \mathrm{~min}^{-1}$. Reverse-phase column applied was Spherisorb ODS-2; $5 \mu \mathrm{m}, 125 \times 4 \mathrm{~mm}$ (Waters Corporation, Milford, MA, USA), while detection was carried out on UV/VIS detector operating at $254 \mathrm{~nm}$ (Jasco, Ishikawa-cho, Japan) The limit of quantification (LLQ) for each compound was set at $0.01 \mathrm{mg} \mathrm{kg}^{-1}$.

\section{HS-SPME extraction of volatile compounds}

The determination of volatile compounds was performed following our previous research in which all conditions were validated as well. ${ }^{9}$ Briefly, $10 \mathrm{~g}$ homogenized fish samples and $10 \mu \mathrm{l}$ of internal standard solution (4-methyl-2-pentanone; $20 \mu \mathrm{g} \mathrm{mL}^{-1}$ ) were weighed into $20 \mathrm{~mL}$ headspace vials and sealed with polytetrafluoroethylene (PTFE)-coated silicone rubber septa (20 mm diameter) (Supelco, Bellefonte, PA, USA). The vials were kept at $7 \pm 1^{\circ} \mathrm{C}$ for at least $1 \mathrm{~h}$ to allow the volatile compounds in the headspace above the sample to reach equilibrium. At the end of the sample equilibration time, a conditioned $\left(1.5 \mathrm{~h}\right.$ at $\left.280{ }^{\circ} \mathrm{C}\right) 85 \mu \mathrm{m}$ Carboxen/polydimethylsiloxane CAR/PDMS) StableFlex fibre (Supelco, Bellefonte, PA, USA) was exposed to the headspace of the sample for volatile compounds extraction (90 min at $25 \pm 2$ ${ }^{\circ} \mathrm{C}$ ) by CombiPAL system injector autosampler (CTC Analytics, Zwingen, Switzerland). These conditions have already been reported. ${ }^{9}$

\section{GC/MS conditions}

Analyses were performed with a TraceGC (Ultra gas chromatograph (Thermo Fisher Scientific, Rodano, Italy) equipped with a Rtx-WAX column $(30 \mathrm{~m} \times 0.25 \mathrm{~mm}$ i.d., $0.25 \mu \mathrm{m}$ film thickness; Superchrom, Milan, Italy) and coupled to a TraceDSQII mass spectrometer (Thermo Fisher Scientific) with source and transfer line temperatures kept at 250 and $200{ }^{\circ} \mathrm{C}$ respectively. The column temperature was set initially at $35^{\circ} \mathrm{C}$ for $8 \mathrm{~min}$, then increased to $60{ }^{\circ} \mathrm{C}$ at $4{ }^{\circ} \mathrm{C}$ min 
${ }^{-1}$, to $160{ }^{\circ} \mathrm{C}$ at $6{ }^{\circ} \mathrm{C} \mathrm{min}{ }^{-1}$ and finally to $200{ }^{\circ} \mathrm{C}$ at $20^{\circ} \mathrm{C} \mathrm{min}{ }^{-1}$ and held for $15 \mathrm{~min}$. Helium was used as the carrier gas at a flow rate of $1 \mathrm{~mL} \mathrm{~min}^{-1}$. The injector temperature was set at 220 ${ }^{\circ} \mathrm{C}$. The splitless mode was used for injection, with a purge time of $8 \mathrm{~min}$. The fibre was maintained in the injection port for $8 \mathrm{~min}$. Electron ionization masses were recorded at $70 \mathrm{eV}$ in the mass range between $\mathrm{m} / \mathrm{z} 35$ and 350. After each analysis the fibre was routinely desorbed at $250{ }^{\circ} \mathrm{C}$ for $15 \mathrm{~min}$ in order to eliminate high-boiling-point contaminants. The identification of the volatile compounds was carried out by comparing their mass spectra with those of standard compounds when available, or by comparing their mass spectra with those stored in the National Institute of Standards and Technology (NIST) US Government Library and with Wiley spectral databases. Analyses were performed in triplicate. Results were expressed as $\mathrm{ng} \mathrm{g}^{-1}$ internal standard equivalents.

\section{Statistical data treatment}

All chemical, microbiological, and Food Sniffer ${ }^{\circledR}$ (FS) data were elaborated statistically. The aim was to investigate different methods of evaluating fish freshness during shelf-life. Especially, the objective was to understand how all the measurements considered change over time and according to temperature, and how chemical and microbiological measurements vary in relation to Food Sniffer ${ }^{\circledR}$ colour changes. To achieve these goals, different data treatment methods were performed: descriptive statistics, $t$ test for the equality of the means, correlation analysis, with both Pearson and Spearman's coefficient, analysis of variance (ANOVA), analysis of reliability (Cronbach's Alpha) and factor analysis (FA). All statistical procedures were carried out using IBM SPSS Statistics 25 (SPSS Inc., Chicago, Il, USA).

\section{RESULTS AND DISCUSSION}




\section{Microbiological Results}

Microbiological results are reported in Table 2, from which it can be noted that some parameters, in particular E.coli and CPS, remain stable throughout sample shelf life and can be classified in the microbiological quality category "satisfactory". Furthermore, L. monocytogens and Salmonella spp. are absent in $25 \mathrm{~g} / \mathrm{sample}$ during the entire duration of the experiment, confirming that there was no primary contamination during handling/processing of the raw samples.

The remaining parameters (total mesophilic and psychrophilic aerobic bacteria and Enterobacteriaceae) instead vary during shelf life and can be classified in the microbiological quality category "unsatisfactory".

\section{Colour and pH trend during shelf-life}

Colour parameter evolution $\left(\mathrm{L}^{*}, \mathrm{a}^{*}, \mathrm{~b}^{*}\right)$ during refrigerated shelf-life is presented in Figure 1. As highlighted in the figure, no significant differences were observed in salmon burger and fillet samples during storage times nor as regards refrigerated conditions. In particular, a correlation analysis using Pearson's correlation coefficients was calculated to better elucidate how the measurements considered changed according to storage Time and Temperature respectively obtaining the following $p$ values: lightness $(0.021 ; 0.015)$, redness $(0.253 ; 0.331)$, yellowness (0.608; 0.123$), p H(0.432 ; 0.579)$. The colour of fish as well as of red meat represents a crucial parameter able to influence consumer choice. Colour changes are essentially due to and in close relation to the quality of fish as well as the storage conditions with a particular focus on temperature, light and the gas composition of the modified atmosphere. Regarding the $\mathrm{pH}$ trend during shelf-life, no significant variations were shown during shelf-life both for salmon fillets and burgers with mean values of 6.28 ranging from a minimum of 6.11 to 6.35 . In addition, a $t$ 
test to verify the equality of means for all colour and $\mathrm{pH}$ variables was performed considering the two different groups (fillet and burger): lightness $(\mathrm{p}$-value $=0.036)$, redness $(\mathrm{p}$-value $=0.000)$, yellowness $(\mathrm{p}$-value $=0.000)$ and $\mathrm{pH}(\mathrm{p}$-value $=0.001)$ and showed statistically significant results. Regarding the colour measurements, these results were expected because of the different production processes as the burgers were produced by grinding the raw muscles, hence determining an oxidation phenomenon with muscle degradation and discoloration as a primary consequence. As regards the descriptive statistics for $p H$ it was observed that this variable has a limited range $(0.17 \mathrm{SD}=0.05)$ for burgers and $(0.18 \mathrm{SD}=0.05)$ for fillets. This result showed that the products were of good quality and correctly managed also during processing and storage phases. Lightness, redness, yellowness and $\mathrm{pH}$ were removed in the following analysis.

\section{Biogenic amine and volatile compounds trends during shelf-life}

The evolution of volatile compounds and biogenic amine detected in salmon fillets and burgers during shelf-life and stored at $4^{\circ} \mathrm{C}$ and $8^{\circ} \mathrm{C}$ are shown in Figure 2 and 3. All volatile compounds expressed in $\mathrm{ng} \mathrm{g}^{-1}$ analysed during storage for the two typologies of fresh salmon are also summarised in Table S1 and S2. To understand how all the measurements considered changed according to Time and Temperature, a correlation analysis (Table S3) was performed computing Pearson's correlation coefficients. All the variables were positively and significantly correlated with Time and Temperature at a significant level of 0.01. Total sulphurates were significantly linked with only five out of fifteen other variables; hence, they were removed in the following analysis. In general, time and storage temperatures are critical factors influencing volatile compound and biogenic amine development as a consequence of degradation phenomena on proteins and lipids. Similar trends as regards biogenic amine were observed for fillets and 
burgers: in particular a high formation of putrescine, cadaverine and histamine was detected in samples stored at $8^{\circ} \mathrm{C}$. As can be observed, the amine content in fillets and burgers stored at $8^{\circ} \mathrm{C}$ is not acceptable in terms of amounts at storage times $\mathrm{T} 3$ and $\mathrm{T} 4$, dramatically different if compared with samples stored at $4^{\circ} \mathrm{C}$. As regards histamine content all samples at T3 and T4 showed a content above the maximum level according to European Regulation 1441/2007 ${ }^{36}$ $\left(100-200 \mathrm{mg} \mathrm{Kg}^{-1}\right)$. Even if putrescine and cadaverine are not regulated as histamine content, they are involved in degradation processes in fish during shelf life and used to determine the fresh index of fish products. ${ }^{37}$ In addition, putrescine, cadaverine, spermine, spermidine in fish tissue can potentiate the toxic effect of histamine by inhibiting intestinal histamine metabolizing enzymes like diamine oxidase. Amines are produced during the end of shelf life and hence their levels can be considered as spoilage indices rather than a quality index. ${ }^{38}$ The usefulness of biogenic amines as a quality index depends on the nature of product. According to Dawood et al. $1988^{39}$, putrescine and cadaverine could be used to assess the freshness of fish such as tuna, salmon and rainbow trout. The limit of fish acceptability for quality index is 10. Considering the biogenic amine content determined at $\mathrm{T} 3$ and $\mathrm{T} 4$ stored at $8^{\circ} \mathrm{C}$, the resulting fresh index consistently exceeding value 10 confirmed the scarce safety and quality condition of stored salmon as well.

Most of the volatile compounds identified in fillets and burgers belonged to the groups of alcohols and ketones with considerable amounts at final storage days and also at $8{ }^{\circ} \mathrm{C}$ storage temperature. In particular, the compounds generated in larger amounts during storage were 3methyl-1-butanol and 3-hydroxy-2-butanone, which are associated with microbial activity as previously highlighted in our research. ${ }^{9}$ 
In addition, even if the trend in terms of evolution seems similar with major formation at final storage times in particular at $8^{\circ} \mathrm{C}$, burger salmon volatile compounds associated with oxidation are more abundant compared to fillets. This is due to the preparation process of fresh fish by grinding the muscle. Hence, mechanical damage leads to early formation of volatile compounds especially those associated with acidity and rancidity, notes responsible for off-flavour in fish (ketones and alcohols).

\section{Food Sniffer ${ }^{\circledR}$ application for rapid evaluation of quality and safety assessment during shelf-life}

Food Sniffer ${ }^{\circledR}$ (FS) functioning and its relationships with other traditional measurements (chemical and microbiological parameters) to quickly detect quality and safety properties such as fish freshness confirm FS as a suitable and rapid support method to screen fish quality during shelf-life. Since FS is a categorical variable, Spearman's correlation, a non-parametric statistical measurement for correlation used for ordinal variables, was performed to investigate its correlations (Table 3). All FS determinations conducted during the entire shelf-life for fillets and burgers stored at $4^{\circ} \mathrm{C}$ and $8^{\circ} \mathrm{C}$ are presented in Table 4 .

The FS device was strongly, positively, and significantly correlated with Time, Temperature, and all the other variables considered. To verify FS evaluation according to the other variables, some descriptive statistics of the conditional distributions of FS are also reported in Table S4. Looking at Table S4 or the means plots, Putrescine, Cadaverine and Histamine did not show great differences when FS appeared "Green" and "Orange", while for the other variables the means were already higher at "Orange" level. Several ANOVA tests were carried out to examine the 
differences in the means in the FS groups for each traditional variable. The averages were always significantly different ( $\mathrm{p}$-values $\leq 0.001)$.

Figure 4 highlights FS behaviour as regards Time and Temperature, and the units are coloured following the FS evaluation. We can observe that until a time of 3 days the bullets are all "Green". At 5 days at $4^{\circ} \mathrm{C} \mathrm{FS}$ is "Green" and at $8^{\circ} \mathrm{C}$ FS is "Orange". At 8 days with $4^{\circ} \mathrm{C}$ storage temperature FS is "Orange" and with $8^{\circ} \mathrm{C} \mathrm{FS}$ is "Red". Finally, at 10 days, the bullets are all "Red". From day 5, at the same Time of Analysis, Temperature triggers the colour, or FS evaluation, change.

Applying the same analysis for Histamine, categorizing it according to its legislative limit, and colouring the bullets as "Green" $<200$ ppm and "Red" $\geq 200$ ppm, obtained the plot shown in Figure 5. In this case, the reaction of the measurement occurs only from a storage time of 8 days with a temperature of $8^{\circ} \mathrm{C}$. This means that Histamine varies only according to Temperature. Although legal limits do not exist for Putrescine and Cadaverine, fixing them arbitrarily at 200 as for Histamine and conducting similar analysis, Putrescine shows the same behaviour as Histamine. A similar trend is observed when examining the results obtained for Cadaverine, but differs according to fish processing typology, since for the salmon burger at 5 days some units are already "Red". Focusing on the conditional distributions of Cadaverine evaluation by FS, it was observed that when FS is "Red" most units are correctly classified "Red" also for Cadaverine. Generally, it can be concluded that the classic analytical measurements for fish freshness based on biogenic amine are slower than FS response to predict alarming quality changes. FS turns "Orange" already at 5 days with a higher temperature and at 8 days with a lower temperature; thus confirming this alternative measure as more sensitive. For practical purposes, it is also important to consider, for its role in food safety, the relationship between FS 
and microbiological parameters. The microbiological variables according to the CeIRSA guidelines (Interdepartmental Centre for Research and Documentation on Food Safety of Piedmont region) are recorded in Table 1. For Pseudomonas spp., a similar classification is not available. It is worth noting that for the Total Bacterial Count at $30^{\circ}$ no units are "Not satisfactory" when FS is "Green", and with FS "Orange" or "Red" there are some "Not Satisfactory"; 75\% of the fish classified "Orange" for FS is "Not satisfactory", and 33\% of the fish classified "Red" for FS is "Acceptable" (Table 5). For the Total Bacterial Count at $22^{\circ}$ the distributions are similar to those for the Total Bacterial Count at $30^{\circ}$, but in this case $10 \%$ of the units are "Not satisfactory" when FS is "Green" (Table 6). The same holds true for Enterobacteriaceae (Table 7).

For a better understanding of the behaviour of the microbiological variables in the three FS groups, the box-plots highlight the differences (Figure 6). Especially, for the "Orange" level the three variables show the most values over the last limit, and they are classified as "Not satisfactory". The Enterobacteriaceae plot shows that $10 \%$ of the units "Green" for the FS that are classified "Not satisfactory" are outliers.

Factor analyses (FA) were also performed to extract latent variables of freshness to be compared with FS. FA method is used to describe variability among observed variables, detecting underlying latent or unobserved variables, called factors. For each FA this allows to reduce dimensions, obtaining a single measurement. To evaluate the reliability of the observed variables, Cronbach's Alpha has to be calculated. This index is a measure of the intercorrelation among indicators, and it is obtained as an average of the correlations. FAs were performed using the principal component method, where the factor weights are computed to extract the maximum 
possible variance. For this reason, the percentage of the variance extracted by the single factors was used as it can be considered as a goodness of fit measurement for this technique.

The first PCA was performed with the three Biogenic Amines measured; the second with the three volatile compounds classes measured, and the last with the four Microbiological Indicators considered. The FA technique produces factor scores, which are the values assumed for every unit by each latent variable. This allows a correlation analysis to be performed between each latent dimension and the FS. The related Spearman's coefficients are summarized in Table S5 and all the relationships are positive and significant. Plotting the obtained factor scores in the corresponding three dimension scatter plots, the relationships among the single factor, the FS evaluation, Time and Temperature can be studied. A plot for the Microbiological factor score is presented in Figure 7.

In general, this factor score increases with Temperature and Time. Until storage time of 3 days, with any Temperature, the bullets are all "Green" and the factor score is lower than, or near to, zero. At 5 days, with $4^{\circ} \mathrm{C}$ temperature, $\mathrm{FS}$ is "Green", and the factor score is lower than zero, while with $8^{\circ} \mathrm{C}$ FS is "Orange" and the factor score is between zero and 1 . At 8 days with $4^{\circ} \mathrm{C}$, FS is "Orange", and the factor score is between zero and 1, while with $8^{\circ} \mathrm{C} \mathrm{FS}$ is "Red", and the factor score is greater than 1 . Finally, at 10 days, the bullets are all "Red", with $4^{\circ} \mathrm{C}$ temperature the factor score is around zero, while with $8^{\circ} \mathrm{C}$ temperature the factor score is greater than 1 . Looking at the factor score scale, it is important to notice that zero is the mean value by construction of the factors. It is evident that the original scale was lost and so these results cannot be read according to legislative limits. Loading the ANOVA for the three factor scores grouping by FS evaluation, the means are significantly different, confirming the previous results (p-values $\leq 0.000$ ). For Biogenic Amines factor score, Figure 8 shows that there are no differences between 
FS "Green" and "Orange", while for the other factors the means are already higher at "Orange" level.

\section{CONCLUSIONS}

In conclusion, the use of the Food Sniffer ${ }^{\circledR}$ application is confirmed as valid support during shelf life as it is able to anticipate the unacceptability conditions of salmon samples also correlated with chemical and microbiological parameters. This could represent a valid support for the food and retail industry to manage perishable food commodities preventing possible food risk as well. This study contributes to current knowledge in the field of smartphone-based food diagnostic technologies in the food sector. This type of fast screening method provides significant advantages over traditional methods in terms of test speed, low cost, ease-of-operation, and data management, and requires minimal equipment and user involvement. However, this study demonstrates that further investigation is indispensable in order to conduct robust scientific validation both of the instrument and its field of application.

\section{REFERENCES}

1 Kris-Etherton PM, Harris WS, and Appel LJ. Fish consumption, fish oil, omega-3 fatty acids, and cardiovascular disease. Circulation 106:2747-2757 (2002).

2 Dale N. National research council nutrient requirements of poultry - ninth revised edition (1994). J. Appl. Poult. Res. 1994.

3 Loreal $\mathrm{H}$ and Lahsen A. Quality of fish from catch to consumer: Labelling, monitoring and traceability. Livest Sci (2006).

4 EUMOFA. The Eu Fish Market 2018. :120 (2018).

5 Lipinski B, Hanson C, Lomax J, Kitinoja L, Waite R, and Searchinger T. Toward a sustainable food system Reducing food loss and waste. World Resour. Inst. 2016.

6 Verbeke W, Sioen I, Pieniak Z, Camp J Van, and Henauw S De. Consumer perception versus scientific evidence about health benefits and safety risks from fish consumption. Public Health Nutr (2005). 
7 Paiva EL de, Alves JC, Milani RF, Boer BS, Quintaes KD, and Morgano MA. Sushi commercialized in Brazil: Organic $\mathrm{Hg}$ levels and exposure intake evaluation. Food Control (2016).

8 Chiesa LM, Nobile M, Ceriani F, Malandra R, Arioli F, and Panseri S. Risk characterisation from the presence of environmental contaminants and antibiotic residues in wild and farmed salmon from different FAO zones. Food Addit Contam - Part A Chem Anal Control Expo Risk Assess (2019).

9 Mazandrani HA, Javadian SR, and Bahram S. The effect of encapsulated fennel extracts on the quality of silver carp fillets during refrigerated storage. Food Sci Nutr (2016).

10 Chan ST, Yao MWY, Wong YC, Wong T, Mok CS, and Sin DWM. Evaluation of chemical indicators for monitoring freshness of food and determination of volatile amines in fish by headspace solid-phase microextraction and gas chromatography-mass spectrometry. Eur Food Res Technol (2006).

11 Kyrana VR and Lougovois VP. Sensory, chemical and microbiological assessment of farm-raised European sea bass (Dicentrarchus labrax) stored in melting ice. Int J Food Sci Technol (2002).

12 Heising JK, Dekker M, Bartels P V., and (Tiny) Van Boekel MAJS. Monitoring the Quality of Perishable Foods: Opportunities for Intelligent Packaging. Crit. Rev. Food Sci. Nutr. 2014.

13 Farber JM. Microbiological aspects of modified-atmosphere packaging technology - A review. J. Food Prot. 1991.

14 Programme F, Union E, Agreement G, and Union E. D4 . 8 A roadmap to reduce food waste in Europe. (2020).

15 Dissaraphong S, Benjakul S, Visessanguan W, and Kishimura H. The influence of storage conditions of tuna viscera before fermentation on the chemical, physical and microbiological changes in fish sauce during fermentation. Bioresour Technol (2006).

16 Soncin S, Chiesa LM, Panseri S, Biondi P, and Cantoni C. Determination of volatile compounds of precooked prawn (Penaeus vannamei)and cultured gilthead sea bream (Sparus aurata) stored in ice as possible spoilage markers using solid phase microextraction and gas chromatography/mass spectrometry. J Sci Food Agric (2009).

17 Castro P, Padrón JCP, Cansino MJC, Velázquez ES, and Larriva RM De. Total volatile base nitrogen and its use to assess freshness in European sea bass stored in ice. Food Control (2006).

18 Emerging Technologies for Food Quality and Food Safety Evaluation. Emerg. Technol. Food Qual. Food Saf. Eval. 2011.

19 Jørgensen LV, Huss HH, and Dalgaard P. Significance of volatile compounds produced by spoilage bacteria in vacuum-packed cold-smoked salmon (Salmo salar) analyzed by GC-MS and multivariate regression. J Agric Food Chem (2001). 
20 Mai NTT, Gudjónsdóttir M, Lauzon HL, Sveinsdóttir K, Martinsdóttir E, Audorff H, Reichstein W, Haarer D, Bogason SG, and Arason S. Continuous quality and shelf life monitoring of retail-packed fresh cod loins in comparison with conventional methods. Food Control (2011).

21 Chiesa L, Panseri S, Pavlovic R, and Arioli F. Biogenic amines evaluation in wild Bluefin tuna (Thunnus thynnus) originating from various FAO areas. J fur Verbraucherschutz und Leb (2018).

22 Arvanitoyannis IS, Tsitsika E V., and Panagiotaki P. Implementation of quality control methods (physicochemical, microbiological and sensory) in conjunction with multivariate analysis towards fish authenticity. Int. J. Food Sci. Technol. 2005.

23 Rateni G, Dario P, and Cavallo F. Smartphone-based food diagnostic technologies: A review. Sensors (Switzerland). 2017.

24 Ramírez HL, Soriano A, Gómez S, Iranzo JU, and Briones AI. Evaluation of the Food Sniffer electronic nose for assessing the shelf life of fresh pork meat compared to physicochemical measurements of meat quality. Eur Food Res Technol (2018).

25 Grassi S, Benedetti S, Opizzio M, Nardo E Di, and Buratti S. Meat and fish freshness assessment by a portable and simplified electronic nose system (Mastersense). Sensors (Switzerland) (2019).

26 Davis LB, Sengul I, Ivy JS, Brock LG, and Miles L. Scheduling food bank collections and deliveries to ensure food safety and improve access. Socioecon Plann Sci (2014).

27 Milicevic V, Colavita G, Castrica M, Ratti S, Baldi A, and Balzaretti CM. Risk assessment in the recovery of food for social solidarity purposes: Preliminary data. Ital J Food Saf (2016).

28 Ólafsdóttir G and Kristbergsson K. Electronic-nose technology: Application for quality evaluation in the fish industry. Odors in the Food Industry 2006.

29 Teklemariam AD, Tessema F, and Abayneh T. Review on Evaluation of Safety of Fish and Fish Products. Int J Fish Aquat Stud 3:111-117 (2015).

30 Huang X, Lv R, Yao L, Guan C, Han F, and Teye E. Non-destructive evaluation of total volatile basic nitrogen (TVB-N) and K-values in fish using colorimetric sensor array. Anal Methods (2015).

31 Haute S Van, Raes K, Meeren P Van der, and Sampers I. The effect of cinnamon, oregano and thyme essential oils in marinade on the microbial shelf life of fish and meat products. Food Control (2016).

32 Kaewprachu P, Osako K, Benjakul S, Suthiluk P, and Rawdkuen S. Shelf life extension for Bluefin tuna slices (Thunnus thynnus) wrapped with myofibrillar protein film incorporated with catechin-Kradon extract. Food Control (2017).

33 Castrica M, Panseri S, Siletti E, Borgonovo F, Chiesa L, and Balzaretti CM. Evaluation of 
smart portable device for food diagnostics: A preliminary study on Cape Hake fillets (M. Capensis and M. Paradoxus). J Chem (2019).

34 Najam ul Hasan, Ejaz N, Ejaz W, and Kim HS. Meat and fish freshness inspection system based on odor sensing. Sensors (Switzerland) 12:15542-15557 (2012).

35 O'Sullivan MG and Kerry JP. Instrumental assessment of the sensory quality of meat, poultry and fish. Instrumental Assessment of Food Sensory Quality 2013.

36 EU Commission. Commission regulation (EC) No 1441/2007 of 5 December 2007 amending Regulation (EC) No 2073/2005 on microbiological criteria for foodstuffs. Off $\boldsymbol{J}$ Eur Union (2007).

37 Biji KB, Ravishankar CN, Venkateswarlu R, Mohan CO, and Gopal TKS. Biogenic amines in seafood: a review. J. Food Sci. Technol. 2016.

38 Özogul F and Özogul Y. Biogenic amine content and biogenic amine quality indices of sardines (Sardina pilchardus) stored in modified atmosphere packaging and vacuum packaging. Food Chem (2006).

39 Dawood AA, Karkalas J, Roy RN, and Williams CS. The occurrence of non-volatile amines in chilled-stored rainbow trout (Salmo irideus). Food Chem (1988). 


\section{Figure Legends}

Figure 1. CIE colour coordinates $\left(\mathrm{L}^{*}, \mathrm{a}^{*}, \mathrm{~b}^{*}\right)$ during the refrigerated shelf-life of salmon fillet and burger.

Figure 2. Biogenic amine trend during the refrigerated shelf-life of salmon fillet and burger.

Figure 3. Volatile compounds (chemical classes) evolution during the refrigerated shelf-life of salmon fillet and burger.

Figure 4. Scatterplot between Time and Temperature, with Food Sniffer® evaluation.

Figure 5. Scatterplot between Time and Temperature, with Histamine evaluation.

Figure 6. Conditional box-plots for microbiological variables according to Food Sniffer ${ }^{\circledR}$.

Figure 7. Three dimensions scatter plot for microbiological factor score by Food Sniffer®, Time and temperature.

Figure 8. Means plot for biogenic amines factor score. 
Table 1. CeIRSA limits for the category "fish and fish preparation" (CeIRSA, 2017).

\section{CeIRSA limits (Log CFU/g)}

\begin{tabular}{|c|c|c|c|c|}
\hline Parameters & Satisfactory & Acceptable & Not satisfactory & Potentially Dangerous \\
\hline Total bacterial count & $<4$ & $4 \leq x<6$ & $\geq 6$ & \\
\hline E. coli & $<1$ & $1 \leq x \leq 2$ & $\geq 2$ & \\
\hline Enterobacteriaceae & $<2$ & $2 \leq x<4$ & $\geq 4$ & \\
\hline Coagulase-positive & $<1$ & $1 \leq \mathrm{x}<2$ & $\geq 2$ & \\
\hline Salmonella spp. & Absence in $25 \mathrm{~g}$ & & & Presence in $25 \mathrm{~g}$ \\
\hline $\begin{array}{l}\text { Listerla } \\
\text { monocytogenes }\end{array}$ & Absence in $25 \mathrm{~g}$ & & & Presence in $25 \mathrm{~g}$ \\
\hline
\end{tabular}

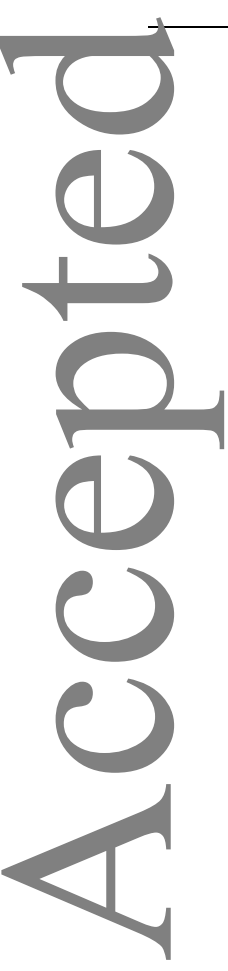




\begin{tabular}{|c|c|c|c|c|c|c|c|c|}
\hline T4 & $8^{\circ} \mathrm{C}$ & $F$ & 8,01 & 7,05 & 4,77 & $<1$ & 5,59 & $<1$ \\
\hline T4 & $8^{\circ} \mathrm{C}$ & $\mathrm{F}$ & 8,70 & 8,30 & 5,39 & $<1$ & 4,92 & $<1$ \\
\hline
\end{tabular}

Table 3. Spearman's correlation coefficients (** significant at 0.01 )

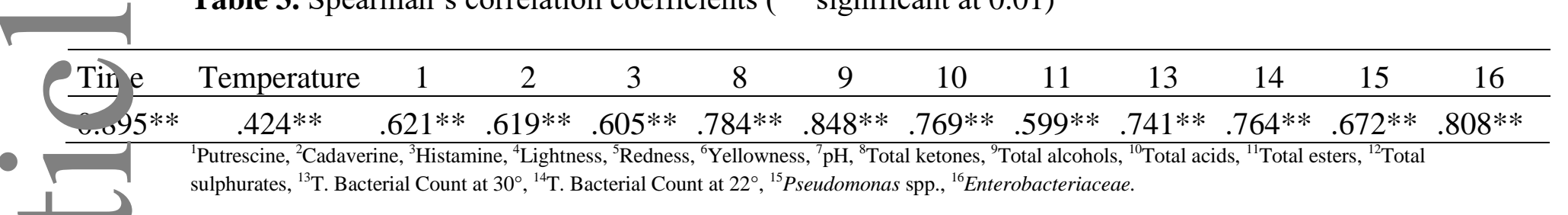

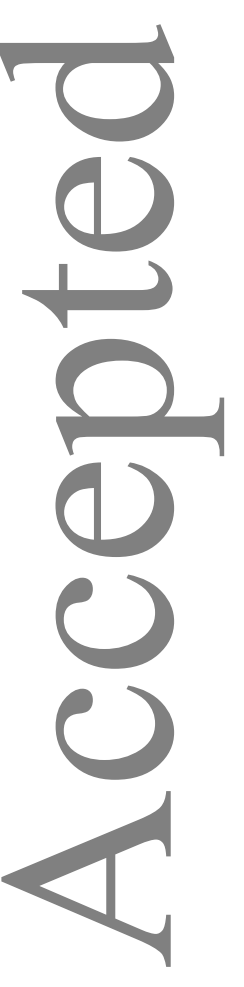


Table 4. Food Sniffer ${ }^{\circledR}$ classification (green, orange, red) in salmon burgers and fillets during shelf-life in two different storage temperatures.

\begin{tabular}{|c|c|c|c|}
\hline $\begin{array}{l}\text { Analysis } \\
\text { Time }\end{array}$ & $\begin{array}{c}\text { Storage } \\
\text { Temperature }\end{array}$ & $\begin{array}{c}\text { Sample Type } \\
\text { (B: burger, F: filet) }\end{array}$ & Food Sniffer ${ }^{\circledR}$ \\
\hline TO & $4^{\circ} \mathrm{C}$ & B & Green \\
\hline TO & $4^{\circ} \mathrm{C}$ & B & Green \\
\hline TO & $4^{\circ} \mathrm{C}$ & B & Green \\
\hline TO & $4^{\circ} \mathrm{C}$ & $\mathrm{F}$ & Green \\
\hline TO & $4^{\circ} \mathrm{C}$ & $\mathrm{F}$ & Green \\
\hline TO & $4^{\circ} \mathrm{C}$ & $\mathrm{F}$ & Green \\
\hline $\mathrm{T} 1$ & $4^{\circ} \mathrm{C}$ & B & Green \\
\hline $\mathrm{T} 1$ & $4^{\circ} \mathrm{C}$ & B & Green \\
\hline $\mathrm{T} 1$ & $8^{\circ} \mathrm{C}$ & B & Green \\
\hline $\mathrm{T} 1$ & $8^{\circ} \mathrm{C}$ & B & Green \\
\hline $\mathrm{T} 1$ & $4^{\circ} \mathrm{C}$ & $\mathrm{F}$ & Green \\
\hline $\mathrm{T} 1$ & $4^{\circ} \mathrm{C}$ & $\mathrm{F}$ & Green \\
\hline $\mathrm{T} 1$ & $8^{\circ} \mathrm{C}$ & $\mathrm{F}$ & Green \\
\hline $\mathrm{T} 1$ & $8^{\circ} \mathrm{C}$ & $\mathrm{F}$ & Green \\
\hline $\mathrm{T} 2$ & $4^{\circ} \mathrm{C}$ & B & Green \\
\hline $\mathrm{T} 2$ & $4^{\circ} \mathrm{C}$ & B & Green \\
\hline $\mathrm{T} 2$ & $8^{\circ} \mathrm{C}$ & B & Orange \\
\hline $\mathrm{T} 2$ & $8^{\circ} \mathrm{C}$ & B & Orange \\
\hline $\mathrm{T} 2$ & $4^{\circ} \mathrm{C}$ & $\mathrm{F}$ & Green \\
\hline $\mathrm{T} 2$ & $4^{\circ} \mathrm{C}$ & $\mathrm{F}$ & Green \\
\hline $\mathrm{T} 2$ & $8^{\circ} \mathrm{C}$ & $\mathrm{F}$ & Orange \\
\hline $\mathrm{T} 2$ & $8^{\circ} \mathrm{C}$ & $\mathrm{F}$ & Orange \\
\hline T3 & $4^{\circ} \mathrm{C}$ & B & Orange \\
\hline T3 & $4^{\circ} \mathrm{C}$ & B & Orange \\
\hline T3 & $8^{\circ} \mathrm{C}$ & B & Red \\
\hline T3 & $8^{\circ} \mathrm{C}$ & B & Red \\
\hline T3 & $4^{\circ} \mathrm{C}$ & $\mathrm{F}$ & Orange \\
\hline T3 & $4^{\circ} \mathrm{C}$ & $\mathrm{F}$ & Orange \\
\hline T3 & $8^{\circ} \mathrm{C}$ & $\mathrm{F}$ & Red \\
\hline T3 & $8^{\circ} \mathrm{C}$ & $\mathrm{F}$ & Red \\
\hline $\mathrm{T} 4$ & $4^{\circ} \mathrm{C}$ & B & Red \\
\hline $\mathrm{T} 4$ & $4^{\circ} \mathrm{C}$ & B & Red \\
\hline T4 & $8^{\circ} \mathrm{C}$ & B & Red \\
\hline T4 & $8^{\circ} \mathrm{C}$ & B & Red \\
\hline $\mathrm{T} 4$ & $4^{\circ} \mathrm{C}$ & $\mathrm{F}$ & Red \\
\hline $\mathrm{T} 4$ & $4^{\circ} \mathrm{C}$ & $\mathrm{F}$ & Red \\
\hline $\mathrm{T} 4$ & $8^{\circ} \mathrm{C}$ & $F$ & Red \\
\hline $\mathrm{T} 4$ & $8^{\circ} \mathrm{C}$ & $\mathrm{F}$ & Red \\
\hline
\end{tabular}


Table 5. Conditional distributions for Total Bacterial Count at $30^{\circ} \mathrm{C}$ according to Food Sniffer ${ }^{\circledR}$ evaluations.

\begin{tabular}{lcccr}
\hline & \multicolumn{3}{c}{ Food Sniffer® evaluation } & \\
\cline { 2 - 4 } Total Bacterial Count at $30^{\circ}$ & Green & Orange & Red & Total \\
\hline Satisfactory & $10.0 \%$ & $0.0 \%$ & $0.0 \%$ & $5.0 \%$ \\
Acceptable & $90.0 \%$ & $25.0 \%$ & $33.3 \%$ & $60.0 \%$ \\
Not satisfactory & $0.0 \%$ & $75.0 \%$ & $66.7 \%$ & $35.0 \%$ \\
\hline
\end{tabular}

Table 6. Conditional distribution for Total Bacterial Count at $22^{\circ} \mathrm{C}$ according to Food Sniffer ${ }^{\circledR}$ evaluations.

\begin{tabular}{lcccr}
\hline & \multicolumn{3}{c}{ Food Sniffer ${ }^{\circledR}$ evaluation } & \\
\cline { 2 - 4 } Total Bacterial Count at 22 & Green & Orange & Red & Total \\
\hline Satisfactory & $5.0 \%$ & $0.0 \%$ & $0.0 \%$ & $2.5 \%$ \\
Acceptable & $85.0 \%$ & $37.5 \%$ & $33.3 \%$ & $60.0 \%$ \\
Not satisfactory & $10.0 \%$ & $62.5 \%$ & $66.7 \%$ & $37.5 \%$ \\
\hline
\end{tabular}

Table 7. Conditional distribution for Enterobacteriaceae according to Food Sniffer® evaluations.

\begin{tabular}{lcccc}
\hline Enterobacteriaceae & \multicolumn{3}{c}{ Food Sniffer ${ }^{\circledR}$ evaluation } & Total \\
\cline { 2 - 4 } & Green & Orange & Red & \\
\hline Satisfactory & $25.0 \%$ & $0.0 \%$ & $0.0 \%$ & $12.5 \%$ \\
Acceptable & $65.0 \%$ & $37.5 \%$ & $33.3 \%$ & $50.0 \%$ \\
Not satisfactory & $10.0 \%$ & $62.5 \%$ & $66.7 \%$ & $37.5 \%$ \\
\hline
\end{tabular}




\section{Figures}

Figure 1.

Salmon burger

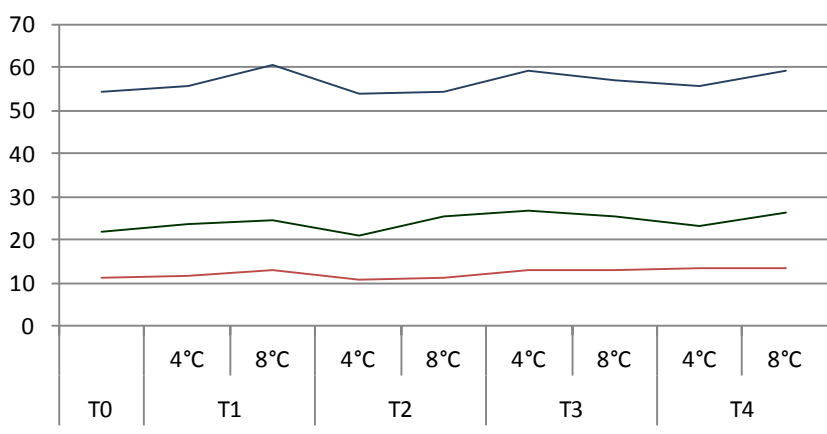

Salmon fillet

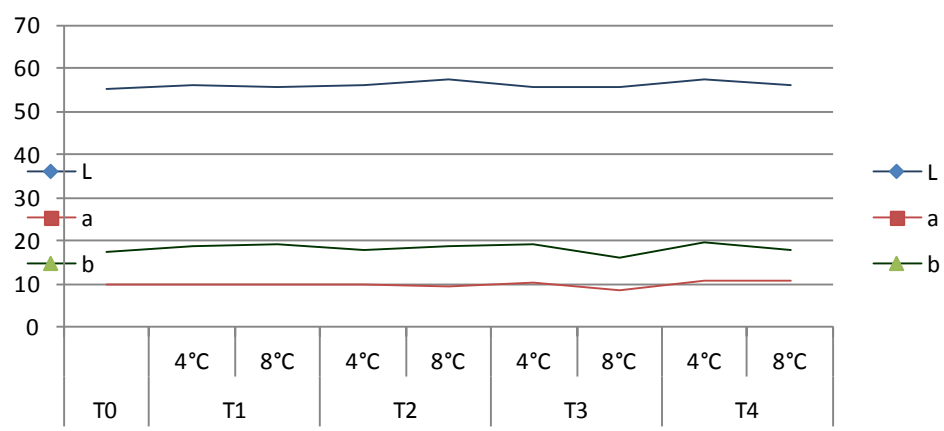

\section{Figure 2.}
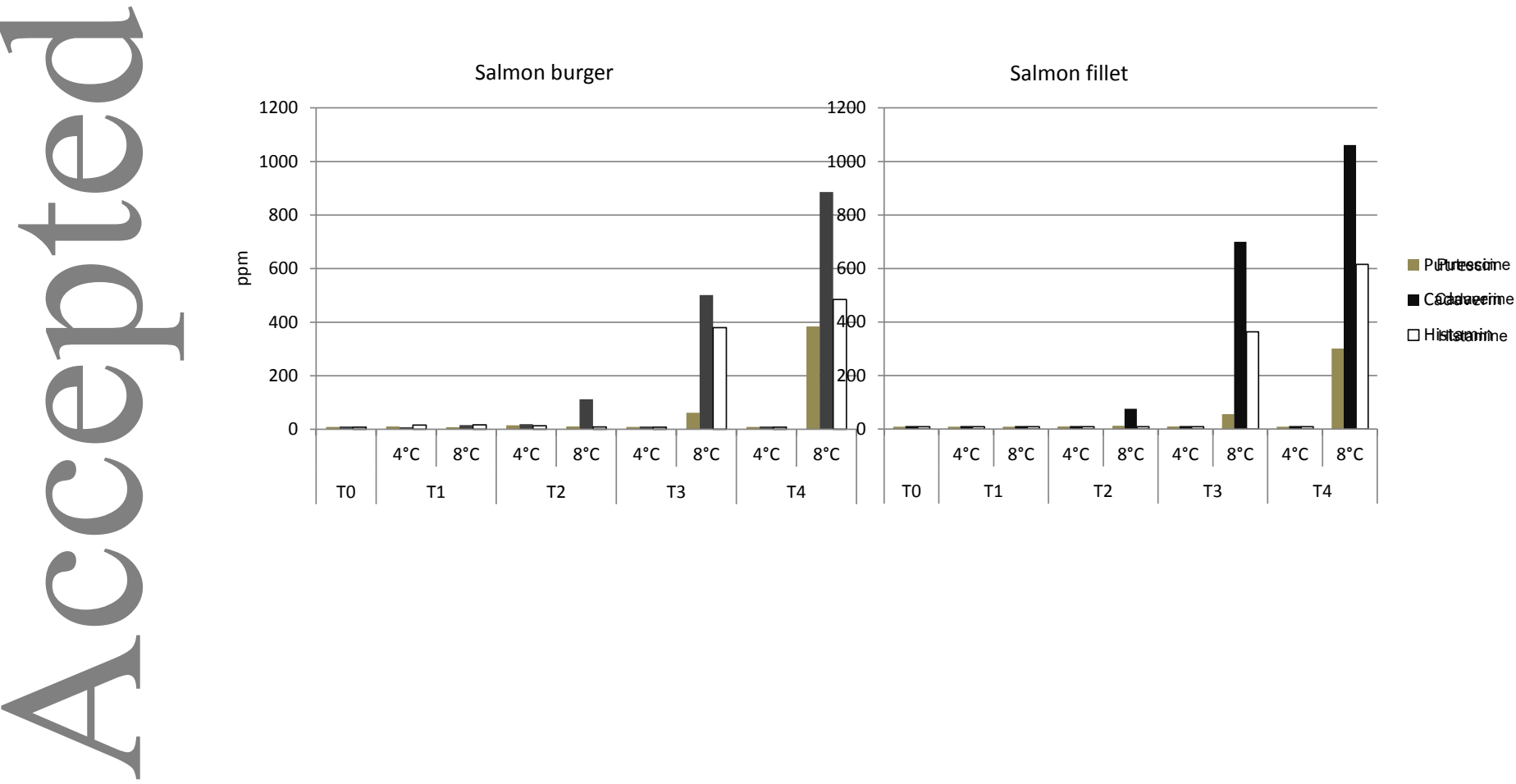

This article is protected by copyright. All rights reserved. 
Figure 3.

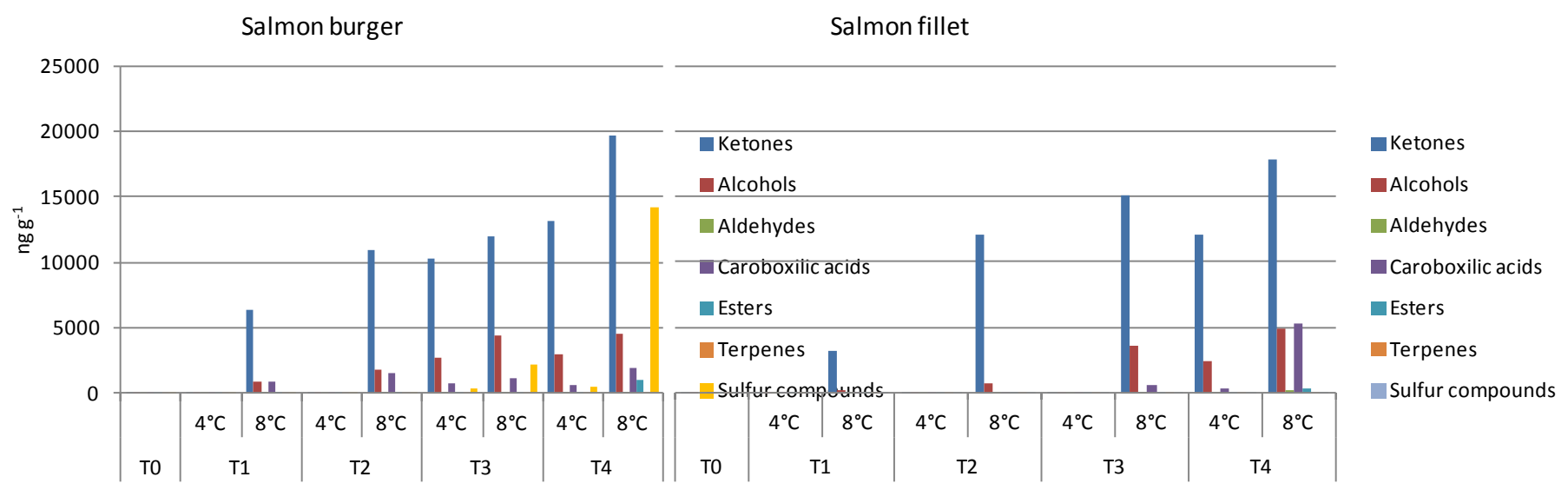

Figure 4.

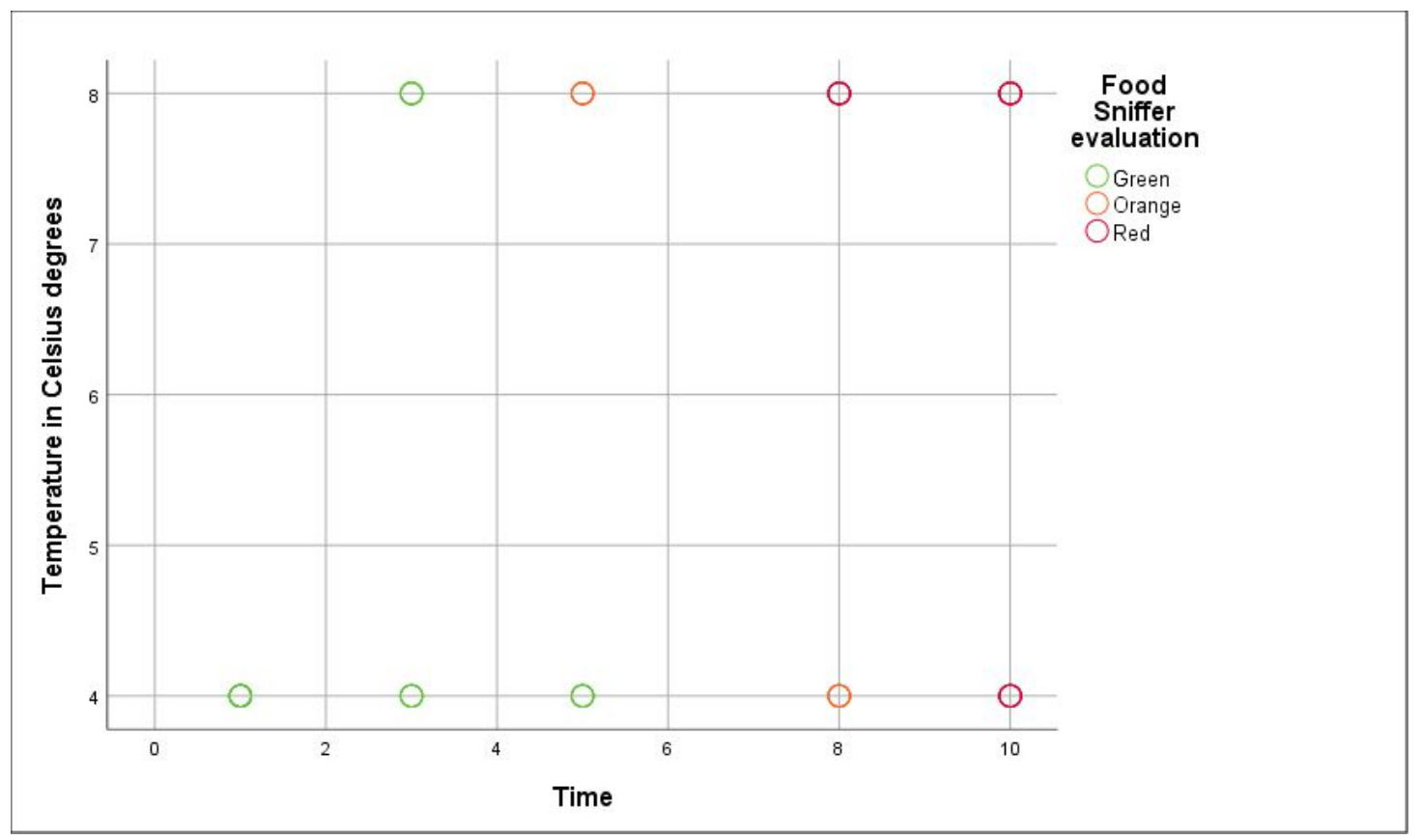

This article is protected by copyright. All rights reserved. 
Figure 5.

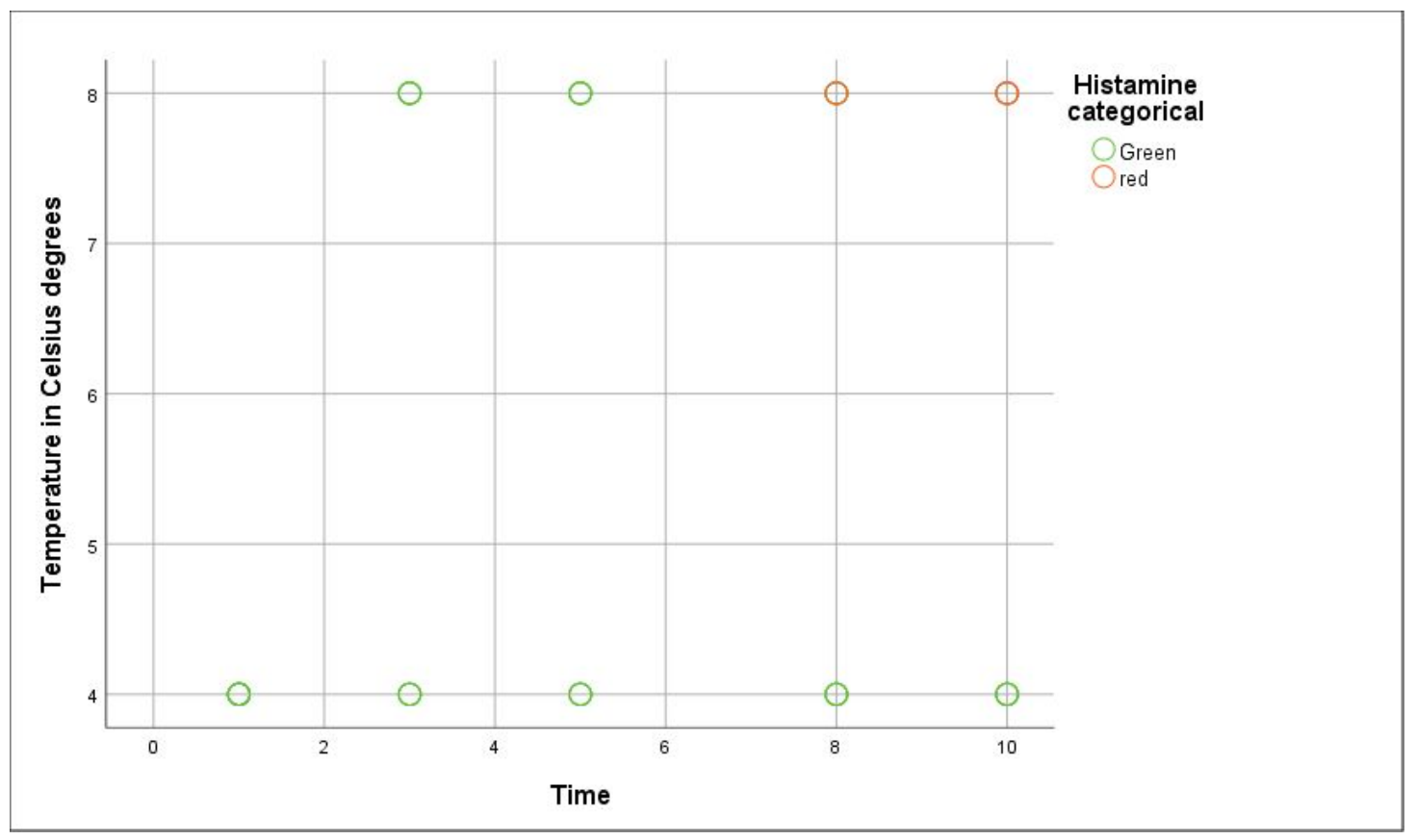

Figure 6.
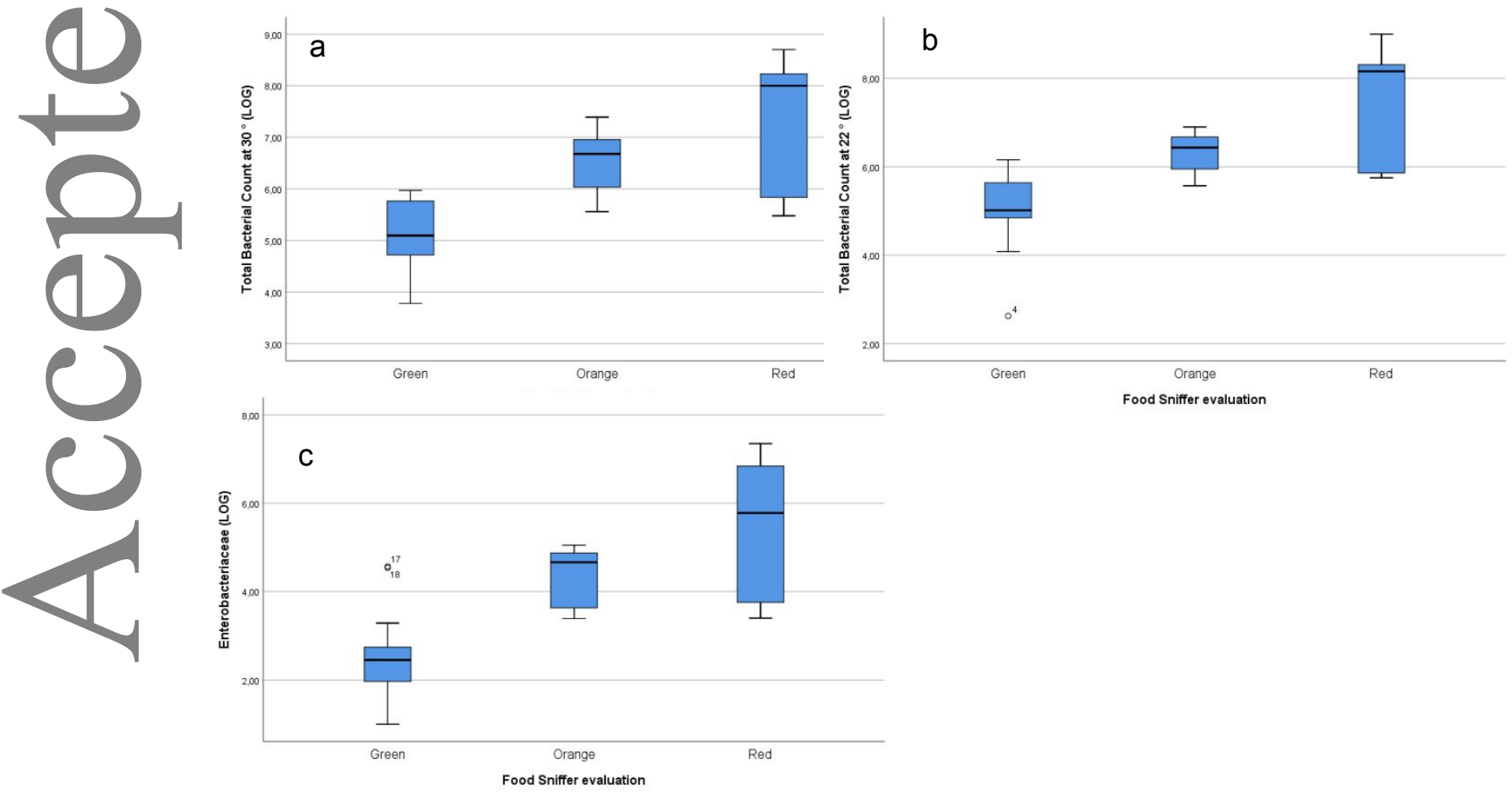

This article is protected by copyright. All rights reserved. 


\section{Figure 7.}

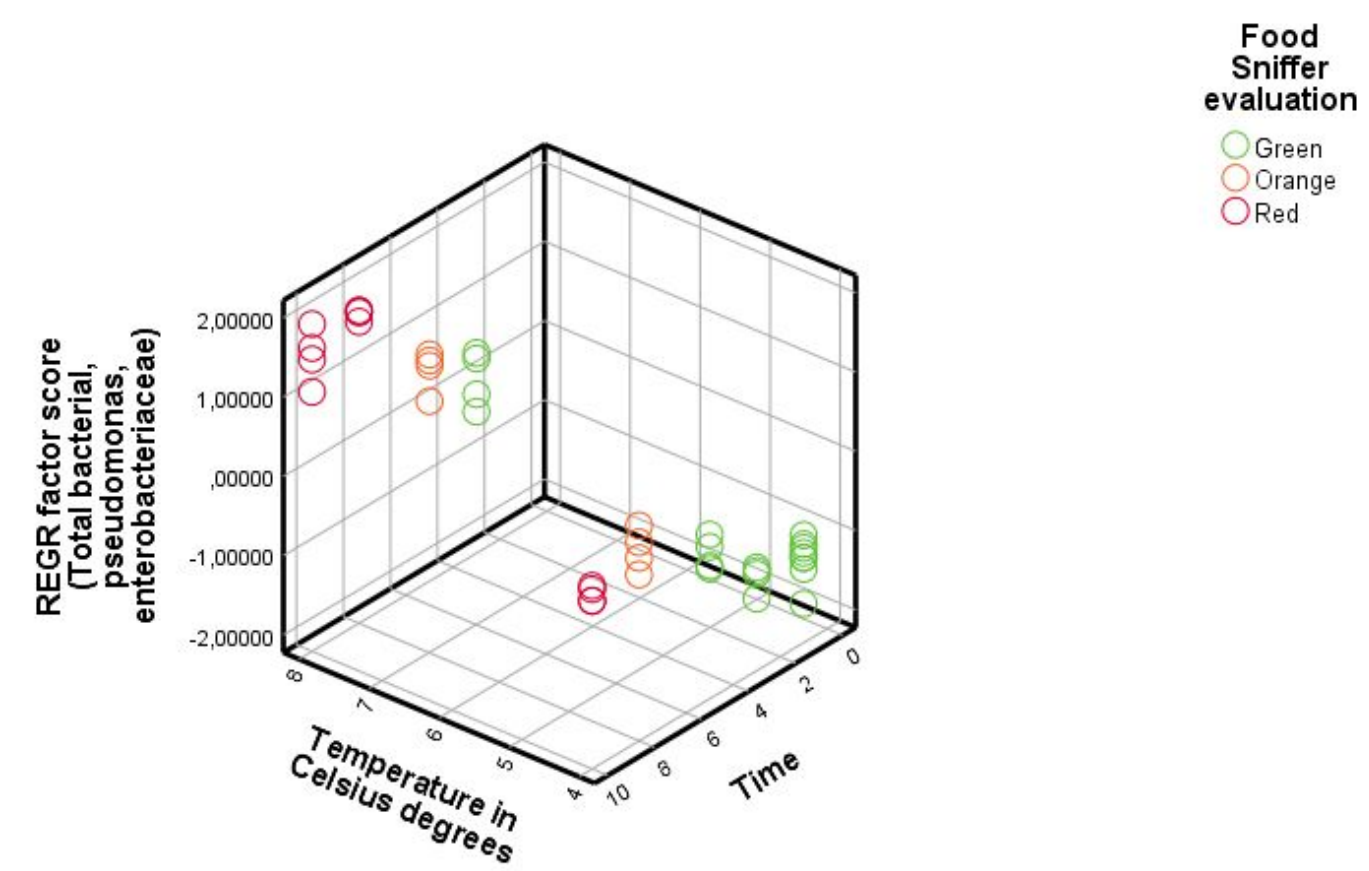

Figure 8.

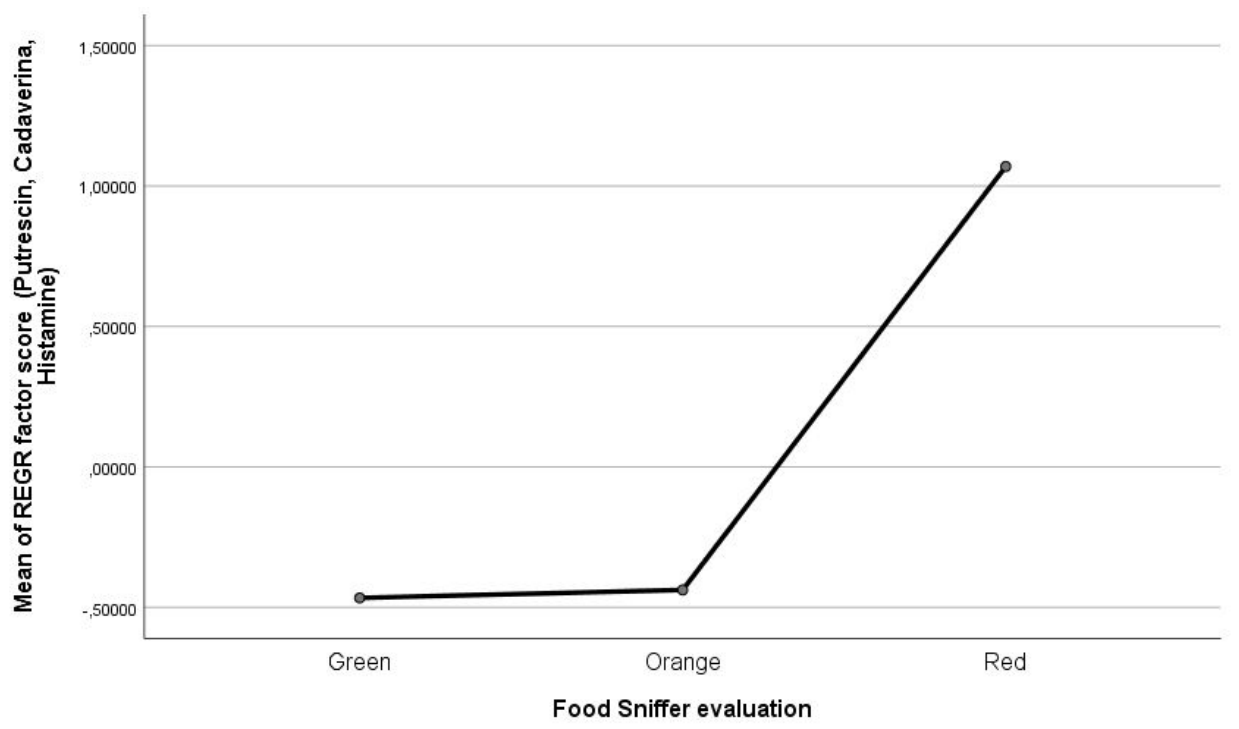

This article is protected by copyright. All rights reserved. 